\title{
Medical education distribution in British Columbia: a thriving partnership
}

\author{
Trina Fyfe, Kristina McDavid, Rebecca Raworth, and David Snadden
}

\section{Introduction}

In the spring of 2008, the University of British Columbia (UBC) graduated 195 [1] students from its distributed undergraduate medical program, the first post-distribution cohort. The distributed program was developed in response to a chronic shortage of physicians in British Columbia [2,3]. The initiative is predicated on a multi-institutional partnership that is the first of its kind in undergraduate medical education in Canada [4]. The partnership currently comprises three sites: the pre-existing Vancouver Fraser Medical Program (VFMP) based at UBC, the Island Medical Program (IMP) based at the University of Victoria (UVic) on Vancouver Island, and the Northern Medical Program (NMP) based at the University of Northern British Columbia (UNBC) in Prince George, which lies approximately $1000 \mathrm{~km}$ north of Vancouver [2].

\section{Program description}

Prior to distribution, the MD undergraduate program at UBC had an intake of 128 students [1,2], with the intention to double enrollment by implementing the distributed program [2]. In 2004, the new distributed program admitted 200 students: 24 in the NMP, 24 in the IMP, and 152 in the VFMP [4]. By 2007, the program doubled its student intake to 256 students, with 32 at each distributed site [4].

Students spend the first semester of the 4-year program in Vancouver at UBC, which gives them an opportunity to connect with their peers before NMP and IMP students travel to their respective sites in January. For the first 2 years of the program, lectures and labs are distributed to each site via videoconference, while problem-based learning (PBL) and clinical skills teaching occur locally. In the third and fourth years of the program, students are dispersed among clinical settings around the province for clerkships and electives.

Library resources and services are planned and delivered cooperatively, with the university libraries and program li- brarians at UNBC, UVic, and UBC acting as local hubs in their respective regions. Accreditation requires that the distributed program provide comparable experiences and resources across the sites; all students and faculty must have access to learning resources, print and electronic, regardless of their location. In March 2008, the MD undergraduate program received a full site visit from the Liaison Committee on Medical Education (LCME) and the Committee on Accreditation of Canadian Medical Schools (CACMS). This visit was the culmination of 2 years of work, including a comprehensive institutional self-study, which required us to clearly outline the library resources and services available at each site. The committee's report was generally positive, even laudatory, but did identify some areas for improvement [5]. Library resources were not noted as a cause for concern, an important benchmark for our collaboration, which is outlined in some detail below.

\section{Planning and governance}

As a committee of the Faculty of Medicine, the Library Operations Committee (LOC) oversees library-related planning, budget, evaluation, and informatics curriculum, and reports to the MD Undergraduate Program Curriculum Committee. LOC membership includes representation from each university library, a librarian from each involved health authority, Faculty of Medicine administrators, Medicine IT, faculty, and students. The committee meets in person twice a year to plan for the continuing growth and further distribution of the program and to discuss successes, challenges, and the budgeting process. While the budget is planned and administered centrally, local sites have a degree of flexibility as to exactly how funds are applied, as long as agreed-upon standards are met. The LOC has been an essential mechanism in the continued development of the program and is a venue for communication and collaboration.

T. Fyfe ${ }^{1}$ and D. Snadden. Northern Medical Program, University of Northern British Columbia, 3333 University Way, Prince George, BC V2N 4Z9, Canada.

K. McDavid. Vancouver Fraser Medical Program, University of British Columbia, 2198 Health Sciences Mall, Vancouver, BC V6T 1Z3, Canada.

R. Raworth. Island Medical Program, University of Victoria, P.O. Box 1800, STN CSC, Victoria, BC V8W 3H5, Canada.

${ }^{1}$ Corresponding author (e-mail: fyfet@unbc.ca). 


\section{Human resources}

A program librarian is based at each university site, and additional staff have been hired as needed. Program librarians have many common responsibilities, but there are also differences based on the needs of the program and site libraries. Common responsibilities include liaison with program students, faculty, staff, and local clinical sites; collection development; research; support; evaluation; and delivery and planning of the informatics curriculum. IMP and NMP librarians are integrated into the main university libraries at their campuses and have liaison responsibilities outside of the medical program. The NMP librarian is also a regular tutor, having led PBL groups in the cardiovascular, reproduction and endocrine, and metabolism blocks. The librarian at UBC is based at the biomedical library and fulfills a coordination role, soliciting library requirements from program faculty and communicating those to the appropriate hospital and university libraries. Each of the program librarians reports jointly to their associate dean and to the leadership of their university library.

The NMP also hired a library technician, reporting to the NMP librarian. This position manages program-related reserves at the UNBC library and helps to support the growing number of clinical sites in the Northern Health Authority. This assistant has become an integral member of the library team and supports the entire program by working on projects such as Web resources and the team's blog. The governance model allows for flexibility in the administration of local sites. For example, while UNBC chose to hire a full-time library assistant, UVic decided to use its funding to purchase portions of several positions, each of which support the program part of the time. All of these roles continue to evolve with the growth of the program.

\section{Collections}

The bulk of the collections supporting the program are materials that have been requested specifically by faculty in support of a particular course or rotation. These requests are coordinated by the program librarian in Vancouver. Prior to the advent of the distributed program, UNBC and UVic libraries were collecting for other health sciences disciplines, but not for a medical school. Both sites have required some investment in basic medical collections outside of reserves and required readings in support of and funded by the MD undergraduate program. The basic medical collections are developed at the discretion of the local program librarians, who are in close contact with local students and faculty through liaison activities.

Some electronic resources have been purchased specifically to support the distributed program, and it has been necessary to increase access (i.e., number of seats) for other popular resources to accommodate the larger student numbers. Usage statistics for individual resources are monitored closely. Electronic access seems ideal at first glance, as students and faculty are distributed across the province. However, Internet access is not always entirely reliable, and some students report that they still find print resources preferable to electronic versions. Furthermore, not all desired materials are available online, not all platforms are desirable, and remote authentication to licensed resources continues to prove challenging.

\section{Curriculum}

Informatics is a curricular theme within the MD undergraduate program and as such is integrated throughout the curriculum, but it does not have its own course. Building on a wellestablished pre-distribution informatics curriculum, program librarians work together to plan and deliver informatics content via lectures, workshops, and assignments, covering topics such as evidence-based medicine, database searching, and critical appraisal. Some activities also rely on the involvement of additional librarian tutors from a variety of local medical libraries. Informatics theme objectives are based on those outlined in the Association of American Medical Colleges (AAMC) Medical School Objectives Project [6]. Program librarians are currently working to align the informatics theme objectives to the Royal College of Physicians and Surgeons in Canada CanMEDS 2005 Physician Competency Framework [7]. In addition, the entire program is undergoing a curriculum review for which an inventory of teaching objectives is being created. The MD undergraduate program librarians are contributing to this process by re-evaluating the informatics curriculum and creating clear, learning-centred objectives for each informatics component. This process will assist in identifying gaps and opportunities for integration and collaboration with specific courses.

\section{Communication and collaboration}

Building strong and sustainable relationships has been critical to the success of the program: communication, respect, trust, and collaboration are key. Over the past 5 years it has become apparent that each program has its unique culture, influenced by its leadership, individual personalities, the "host" institution, and the community it serves. Program librarians strive to be sensitive to the differences at each site in order to provide the best service and resources to students across the program regardless of location. Program librarians set time aside for face-to-face meetings, regular teleconferences, videoconferences, occasional in-person team workshops, as well as some social time. Program librarians also work to be as well connected as possible within the MD undergraduate program through committee work and liaison with faculty. Staff contacts, such as program assistants, information technology, and assessment and evaluation staff are also essential to our success. Student input is valued and sought formally through advisory groups, surveys, and student representation on the LOC.

\section{Health authority libraries}

The distribution and expansion of the medical program has had a significant impact on many of the health authority libraries in the province. Health authority librarians have been and continue to be integral to the planning process. Libraries at clinical education sites receive funding to support collection development for MD undergraduate program students. Librarians at the clinical sites work closely with program librarians at the VFMP, NMP, and IMP to ensure that student and clinical faculty collection needs are being satisfied.

\section{Outcomes}

Over the past 5 years, the libraries have navigated many unknowns and encountered many challenges. Happily, some 
significant successes have been achieved. The LCMECACMS site visit in March 2008 was an important milestone for the program and for our team. Program assessments and evaluations have shown comparable student performance and perceptions across the three sites [8].

\section{Conclusion}

The distributed MD undergraduate program was designed to enable the training of more physicians in British Columbia and to encourage more physicians to practice in the rural and remote areas of the province. It relies on a strong partnership amongst three of the province's universities and several health authorities. The libraries involved came together to form a partnership of their own that owes its success to centralized planning and governance tempered by a degree of local autonomy, trust, respect, and careful communication. Future directions include further exploration of the integrated clerkship model, as well as development of a whole new site based at UBC Okanagan in British Columbia's southern interior.

The NMP is currently piloting an integrated clerkship in Terrace at the Terrace Mills Memorial Hospital, northwest of Prince George, and additional northern sites will be developed based on this model. This pilot has required creative approaches to provision of library resources (both print and electronic) and support for students, staff, and clinical faculty in Terrace, with a focus on long-term sustainability.

In September 2008, the Province of British Columbia announced further expansion and distribution of the program to the Okanagan. The Southern Medical Program (SMP) is scheduled to admit its first class in 2011, with an initial intake of 32 students. The SMP will be comparable to the IMP, NMP, and VFMP with regard to program delivery and will be hosted by UBC Okanagan and Interior Health [9]. The new sites will provide an opportunity to put lessons learned into practice, while striving to improve and refine existing services across the program.

\section{References}

1. Highlights of the progress and evaluation of the distributed expansion. Medicine Matters [serial online]. 2008 Jul [cited 2009 Mar 19];2(1). Available from: http://www.med.ubc.ca/__shared/ assets/Medicine_Matters_July_20087041.pdf.
2. Snadden D, Bates J. Expanding undergraduate medical education in British Columbia: a distributed campus model. CMAJ [serial online]. 2005 Sep [cited 2009 Feb 25];173(6). Available from: http://www.cmaj.ca/cgi/data/173/6/589/DC1/1.

3. McBride BC, Cairns J. Meeting BC's needs for physicians: a vision for medical education in British Columbia [media release on the Internet]. Vancouver: University of British Columbia; 2001 [cited 2009 Mar 19]. Available from: http://www. publicaffairs.ubc.ca/media/releases/2001/mr-01-08c.html.

4. Bates J. Medical school expansion in BC. BCMJ [serial online]. 2008 Sep [cited 2009 Feb 25];50(7):368-70. Available from: http://www.bcmj.org/september-2008.

5. Stewart G. Accreditation Memo [letter on the Internet]. Vancouver: University of British Columbia; 2008 [cited 2009 Mar 19]. Available from: http://www.med.ubc.ca/_shared/assets/ Memorandum_from_Dean_Gavin_Stuart_-_Accreditation_report 7676.pdf.

6. Report I: learning objectives for medical student education: guidelines for medical schools [monograph on the Internet]. Washington: Association of American Medical Colleges; 1998 [cited 2009 Mar 19]. Available from: https://services.aamc.org/ Publications/showfile.cfm?file=version87.pdf\&prd_id=198\&prv_ id=239\&pdf_id=87.

7. The CanMEDS 2005 Physician Competency Framework [monograph on the Internet]. Ottawa: The Royal College of Physicians and Surgeons in Canada; 2005 [cited 2009 Mar 19]. Available from: http://rcpsc.medical.org/canmeds/CanMEDS 2005/index.php.

8. Lovato CY, Murphy CC. Comparability of student performance and experiences in UBC's distributed MD undergraduate program: the first 2 years. $B C M J$ [serial online]. 2008 Sep [cited 2009 Feb 25];50(7):380-83. Available from: http://www.bcmj.org/september-2008.

9. Office of the Premier. Construction begins on new Southern Medical School [news release on the Internet]. Victoria: [B.C.] Ministry of Advanced Education and Labour Market Development; 2008 [cited 2009 Mar 31]. Available from: http:// www2.news.gov.bc.ca/news_releases_2005-2009/2008OTP0228001427.htm. 
This article has been cited by:

1. Phinney Jackie. 2013. Library Usage Habits of First- and Second-year Medical Students at a Satellite Campus: Report on an Exploratory Questionnaire1. Journal of the Canadian Health Libraries Association 34:03, 147-152. [Abstract] [Full Text] [PDF] [PDF Plus] 